\title{
Anodic Voltammetry of Ciprofloxacin and its Analytical Applications
}

\author{
Bengi Uslu*, Burcin Bozal and Mehmet Emin Kuscu
}

Ankara University, Faculty of Pharmacy, Department of Analytical Chemistry, 06100, Tandogan, Ankara, Turkey

\begin{abstract}
The electrooxidative behavior and determination of ciprofloxacin at a glassy carbon electrode were investigated using cyclic, linear sweep, differential pulse and square wave voltammetric techniques. The dependence of the peak current and peak potentials on $\mathrm{pH}$, concentration, nature of buffer, and scan rate were examined. The oxidation of ciprofloxacin gave a single and irreversible peak at glassy carbon electrode. The process was diffusion controlled. A linear response was obtained between $1.0 \times 10^{-6}$ and $4.0 \times 10^{-5} \mathrm{M}$ in $0.1 \mathrm{M}$ sulphuric acid for both techniques. The recovery studies were also achieved to check selectivity and accuracy of the methods. The proposed methods were applied for the determination of ciprofloxacin from pharmaceutical dosage forms without any time-consuming extraction, separation, adsorption steps. The repeatability, reproducibility, precision and accuracy of the proposed methods were investigated.
\end{abstract}

Keywords: Ciprofloxacin, voltammetry, glassy carbon electrode, pharmaceutical dosage form.

\section{INTRODUCTION}

Fluoroquinolones are important antibacterial group drugs developed in recent years which have been widely used for treatment of many bacterial infections. Broad spectra of activity and good oral absorption have led to extensive clinical use of the newer fluoroquinolones.

The ciprofloxacin hydrochloride (CIP) (Scheme 1) chemically described as 1-cyclopropyl -6-fluoro-1,4-dihydro-4-oxo-7-(1-piperazinyl)-3-quinoline carboxyclic acid, monohydrochloride. CIP is used to treat or prevent certain infections caused by bacteria. CIP is also used to treat or prevent anthrax in people who may have been exposed to anthrax germs in the air [1-3].<smiles>O=C(O)c1cn(C2CC2)c2cc(N3CCNCC3)c(F)cc2c1=O</smiles>

Scheme 1. Chemical structure of ciprofloxacin $\mathrm{HCl}$.

High performance liquid chromatography [4-22], high performance thin layer chromatography $[23,24]$, spectrofluorimetry [25], atomic absorption spectrometry [26], Rayleigh light scattering technique [27] have been utilized for the determination of ciprofloxacin, but complicated preconcentration or multi-solvent extraction technique is also couple with these technique due to the complexity of the real samples and the low concentration of the analyte.

*Address correspondence to this author at the Department of Analytical Chemistry, Faculty of Pharmacy, Ankara University, 06100, Tandogan, Ankara, Turkey; Tel: +90 312- 2033-178; Fax: +90 312-2238-243;

E-mail: buslu@pharmacy.ankara.edu.tr
Electroanalytical methods have long been used for the determination of a wide range of drug compounds due to their simplicity, low cost, and relatively short analysis time when compared to other techniques. Additional application of electrochemistry includes the determination of electrode mechanism [28-31]. Redox properties of organic molecules can give insights into their metabolic fate or their in vivo redox processes or pharmacological activity. Such use of electroanalytical measurements has found a vast of applications, including environmental monitoring, determination of a wide range of drug compounds [32-36], industrial quality control or biomedical analysis [37]. Glassy carbon electrodes are the most common carbon-based electrodes, since they have excellent mechanical and electrical properties, wide potential range, chemically inert nature, and impermeability to gases. They are easily mounted, polishable, and compatible with all common solvents. Their performances are relatively reproducible. Thus, they offer many applications in many different areas.

To our knowledge only one electroanalytical method for ciprofloxacin identification has been reported [38]. In this study authors have been mentioned only qualitative determination of ciprofloxacin in commercial dosage formulations. Also differential-pulse adsorptive stripping voltammetric method has been reported for enrofloxacin in pharmaceutical formulations [39]. Only few biosensor studies have been investigated for ciprofloxacin [40-42].

This work describes the development of a new, simple, rapid and selective voltammetric method to directly determine the ciprofloxacin concentration in pharmaceuticals. The aim of this study is also to investigate the voltammetric behavior and oxidation mechanism at glassy carbon electrode using cyclic, differential pulse and square wave voltammetry.

\section{EXPERIMENTAL}

\subsection{Reagents}

Ciprofloxacin hydrochloride (CIP) standard was kindly supplied by Biopharma (Istanbul, Turkey). The other 
chemicals were reagent grade (Merck or Sigma). A $1 \times 10^{-3}$ $\mathrm{M}$ stock solution of ciprofloxacin was prepared in methanol and kept in the dark in a refrigerator. Working standards of ciprofloxacin were freshly prepared just before the assay, by adding appropriate amounts of stock solution with selected supporting electrolytes so that in most instances the final solution contained $20 \%$ methanol. As supporting electrolytes, sulphuric acid $(0.1 \mathrm{M}$ and $0.5 \mathrm{M})$, phosphate buffer ( $\mathrm{pH}$ 1.45-8.00), Britton Robinson buffer ( $\mathrm{pH} 2.00$ 12.00) and acetate buffer ( $\mathrm{pH} 3.70-5.70)$ were used.

All solutions were kept in the dark and were used within $24 \mathrm{~h}$ to avoid decomposition. However, voltammograms of the samples solutions recorded a week after preparation did not show any appreciable change in assay values.

\subsection{Voltammetric Measurements}

All voltammetric measurements were performed using a BAS 100W electrochemical analyzer (Bioanalytical System, USA). The three electrode system used in this study contained a glassy carbon electrode (BAS ; $\phi: 3 \mathrm{~mm}$, diameter), a platinum wire counter electrode and $\mathrm{Ag} / \mathrm{AgCl}$ $(\mathrm{NaCl} 3 \mathrm{M}, \mathrm{BAS})$ reference electrode and a standard onecompartment three-electrode cell of $10 \mathrm{~mL}$ capacity were used in all experiments. Before each experiment, the glassy carbon electrode was polished manually for the cleaning of the electrode surface with slurries prepared from $0.01 \mu \mathrm{m}$ aluminum oxide on a smooth polishing pad (BAS velvet polishing pad), then was rinsed with double-distilled water thoroughly.

For analytical application, the following parameters were employed: SW voltammetry pulse amplitude, $25 \mathrm{mV}$; frequency, $15 \mathrm{~Hz}$; scan increment, $4 \mathrm{mV}$. DPV parameters were: pulse amplitude, $50 \mathrm{mV}$; pulse width $50 \mathrm{~ms}$; scan rate, $20 \mathrm{mV} \mathrm{s}^{-1}$. The $\mathrm{pH}$ was measured using a $\mathrm{pH}$ meter Model 538 (WTW, Austria) using a combined glass electrode with an accuracy of $\pm 0.05 \mathrm{pH}$.

\subsection{Tablet Assay Procedure}

Ten tablets were thoroughly grounded to a fine powder. A sufficient amount of the powder accurately weighted, to prepare a stock solution including $1 \times 10^{-3} \mathrm{M}$ CIP, transferred to a $100 \mathrm{~mL}$ of calibrated flask, and completed to the volume with methanol. The prepared solution was sonicated for $20 \mathrm{~min}$ to complete dissolution. The sample taken from the clear supernatant liquor was diluted with the selected supporting electrolyte containing a constant amount of methanol $(20 \%, \mathrm{v} / \mathrm{v})$. This solution was used to receive voltammograms by using the selected techniques for glassy carbon electrode. The nominal content of the tablet amounts were calculated from the corresponding regression equations of previously plotted calibration plots for only glassy carbon electrode.

\subsection{Recovery Studies from Tablets}

To study the accuracy of the proposed method, and to check the possible interferences from common excipients, recovery studies were carried out. If the proposed method is used to measure an analyte in a complex sample matrix, a standard addition recovery method can be used. For this purpose, known amounts of the pure ciprofloxacin were added to the pre-analyzed tablet dosage forms. The mixtures were analyzed as in pure ciprofloxacin. After five repeated experiments, the recovery results were calculated using the calibration equation.

\section{RESULTS AND DISCUSSION}

In order to characterize the electrochemical oxidation behavior of CIP, cyclic (CV) and linear sweep voltammetry (LSV) were carried out in the potential range of $0.0-1.7 \mathrm{~V}$. $\mathrm{CV}$ experiments were achieved over a range from acidic $(0.1$ $\mathrm{M}$ and $0.5 \mathrm{M}$ sulphuric acid) to alkaline $(\mathrm{pH}$ 12.00) in different buffer aqueous media at glassy carbon electrode. Differential pulse (DP) and square wave (SW) voltammetric techniques were developed for the determination of CIP for glassy carbon electrode.

The CIP was electrochemically oxidized in a broad $\mathrm{pH}$ range $(0.30-8.00)$ using glassy carbon electrode. The cyclic voltammetric behavior of CIP yielded one well-defined peak in all buffer solutions (Fig. 1). No cathodic peak was observed. In this contribution, only anodic process will be discussed and the peak potential and peak current were determined in supporting electrolyte to maintain solubility. Maximum peak currents for CIP were obtained using $0.1 \mathrm{M}$ sulphuric acid solution which has been successfully used for determination by measuring the peak current at peak potential of 1.12 and $1.16 \mathrm{~V}$ for DPV and SWV, respectively.

Cyclic voltammetric measurements showed an irreversible nature of the oxidation process on glassy carbon electrode (Fig. 2). The scanning was started at $0.0 \mathrm{~V}$ in the positive direction at $0.1 \mathrm{M}$ sulphuric acid, the anodic oxidation of CIP did not occur until about $+1.17 \mathrm{~V}$. By reversing at $+1.7 \mathrm{~V}$, no reduction wave or peak corresponding to the anodic wave was observed on the cathodic branch. CIP peak was decreased by the second and consecutive cycles (Fig. 2). This phenomenon may be partly attributed to the consumption of adsorbed CIP on the electrode surface.

Fig. (3) shows the cyclic voltammograms where the effect of $\mathrm{pH}$, both on the peak potential and on the peak current is clearly seen and agrees with the expected behavior for proton-dependent process coupled to a final irreversible chemical reaction. This chemical irreversibility leads to the absence of any reduction peak in the reverse scan, even if the rate $(v)$ is increased to $1000 \mathrm{mVs}^{-1}$.

Linear Randles-Sevcik plot (plot of $i_{p}$ against $v^{1 / 2}$, correlation coefficient 0.990 for $0.1 \mathrm{M}$ sulphuric acid solutions) was obtained indicating that diffusion is the means of mass transport [43]. This finding was further confirmed by plotting $\log \mathrm{i}_{\mathrm{p}}$ against $\log v$; a straight line was obtained (correlation coefficient 0.996 for $0.1 \mathrm{M}$ sulphuric acid solutions) with a slope of 0.505 (slopes of 0.50 and 1.0 are expected for ideal reactions of solution and surface species) [43].

The plot of the peak potential versus $\mathrm{pH}$ showed a two straight lines between $\mathrm{pH}$ 0.3-6.00 and 6.00-8.00 which can be expressed by the following equation.

$\operatorname{Ep}(\mathrm{mV})=-66.714 \mathrm{pH}+1264.70 \mathrm{r}=0.974, \mathrm{n}=11$

(between $\mathrm{pH}$ 0.30-6.00)

Ep $(\mathrm{mV})=-43.000 \mathrm{pH}+1121.70 \mathrm{r}=0.999, \mathrm{n}=3$ (between $\mathrm{pH}$ 6.00-8.00) 


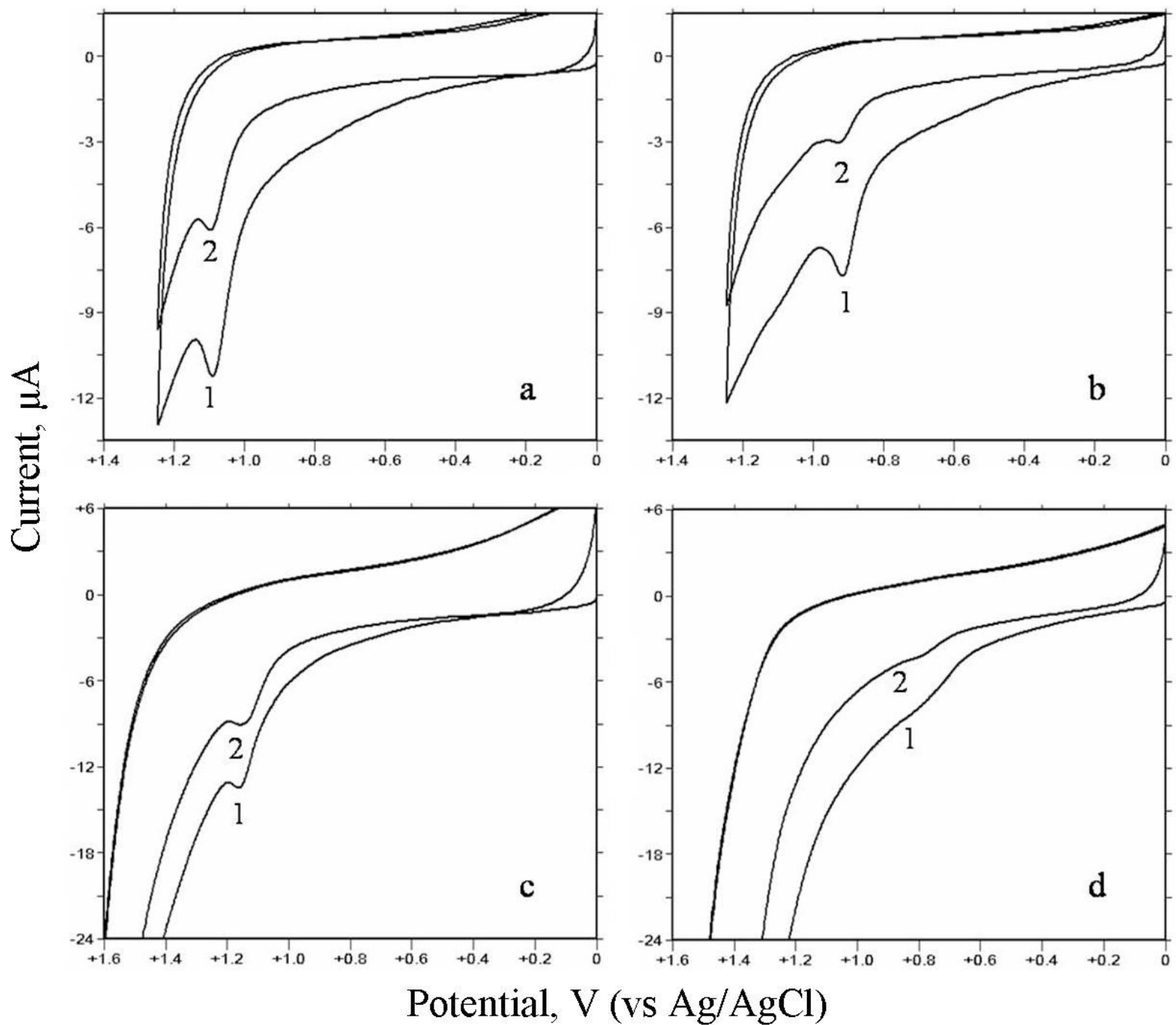

Fig. (1). Repetitive cyclic voltammograms of $2.0 \times 10^{-5} \mathrm{M}$ ciprofloxacin. (a) $\mathrm{pH} 3.00$ phosphate buffer solution, (b) $\mathrm{pH} 4.70$ acetate buffer solution, (c) pH 2.00 BR buffer solution and (d) pH 8.00 BR buffer solution. Scan rate $100 \mathrm{mVs}^{-1}$. (1) first cycle (2) second cycle.

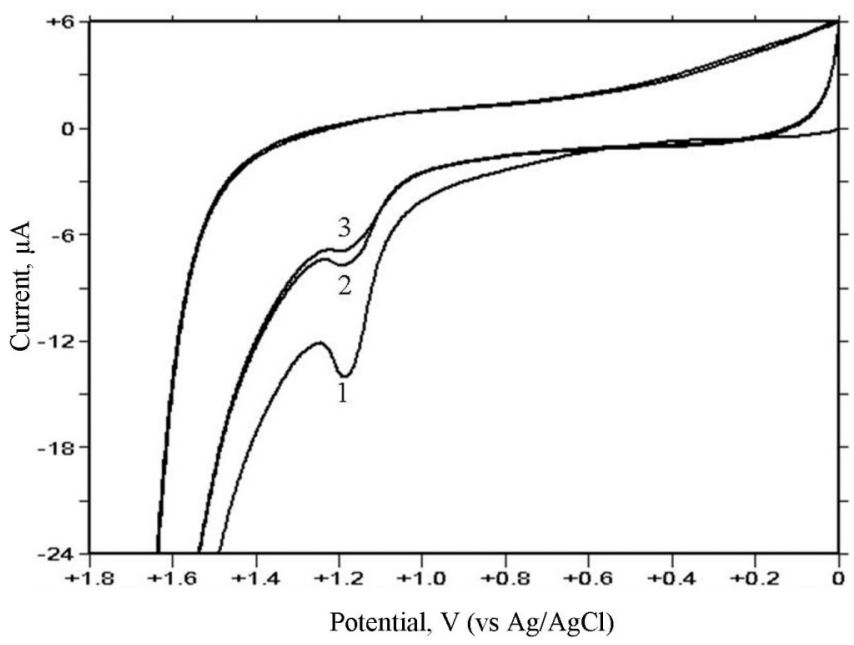

Fig. (2). Repetitive cyclic voltammogram of $2.0 \times 10^{-5} \mathrm{M}$ ciprofloxacin in $0.1 \mathrm{M} \mathrm{H}_{2} \mathrm{SO}_{4}$. Scan rate $100 \mathrm{mVs}^{-1}$. (1) first cycle (2) second cycle (3) third cycle.

The first intersection point of the Ep - pH curves is observed from Fig. (3a) that was reported as pKa1 6.09 and
$\mathrm{pKa}_{2} 8.62$ [44]. However the second intersection point of curve could not be observed because of after $\mathrm{pH} 8.00$ the peak was disappeared.

The peak potential was also dependent on scan rate. The peak potential was shifted to $50 \mathrm{mV}$ positive values on increasing scan rate, which confirms the irreversible nature of the oxidation process. The relation between $\mathrm{E}_{\mathrm{p}}$ and $\log v$ can be expressed by the equation for $0.1 \mathrm{M}$ sulphuric acid solution.

$\operatorname{Ep}(\mathrm{mV})=21,026 \log v+1073.1 \mathrm{r}=0.995 \mathrm{n}=10$

The plot of Ep versus $\log v$ was linear with a correlation coefficient 0.995 . This behavior is consistent with the EC nature of the reaction in which the electrode reaction is coupled with an irreversible follow-up chemical step [45, 46].

The relationship between $\mathrm{pH}$ and CIP current $\left(\mathrm{I}_{\mathrm{p}}\right)$ was also studied. The peak intensity increased in $0.1 \mathrm{M}$ sulphuric acid solutions. For this reason, $0.1 \mathrm{M}$ sulphuric acid solutions were chosen with respect to single and sharp 

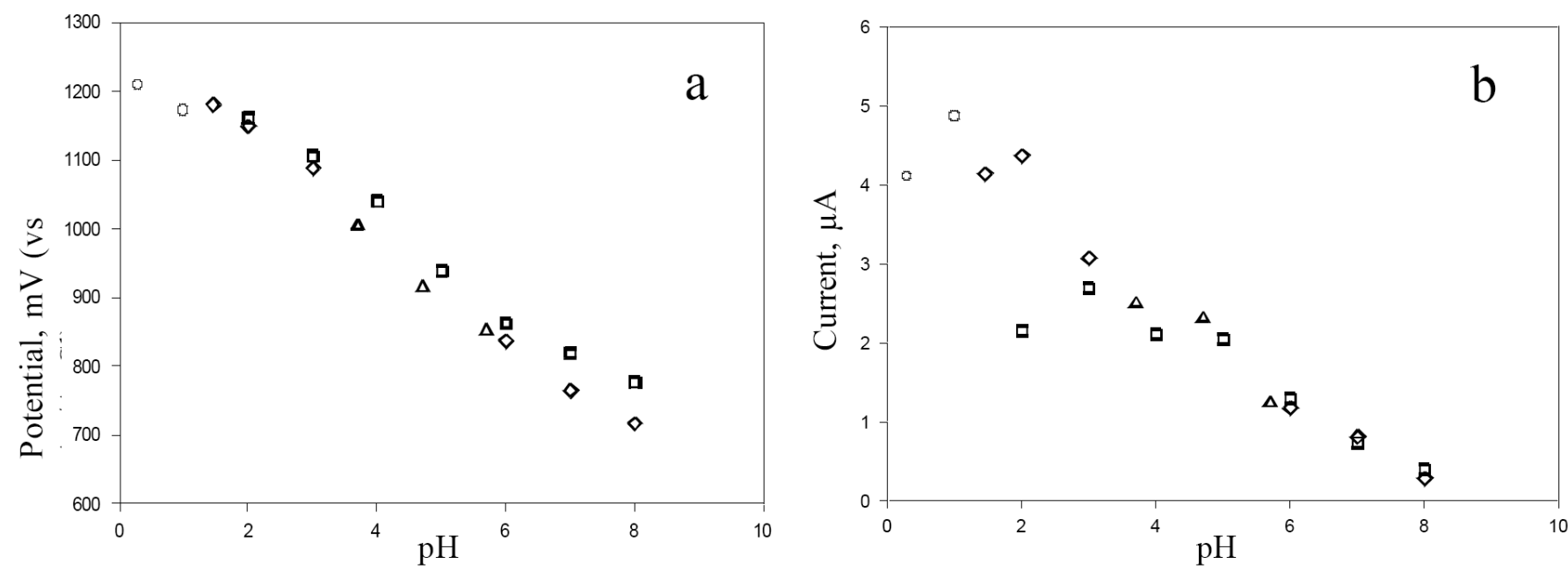

Fig. (3). Effect of $\mathrm{pH}$ on ciprofloxacin peak potential (a) and peak current (b); ciprofloxacin concentration $2.0 \times 10^{-5} \mathrm{M}$. (o) $0.5 \mathrm{M}$ sulphuric acid; ( ) $0.04 \mathrm{M}$ Britton-Robinson buffers; $(\diamond) 0.2 \mathrm{M}$ phosphate buffer; $(\Delta) 0.2 \mathrm{M}$ acetate buffer.

response and better peak shape for the analytical application using cyclic voltammetric technique.

\subsection{Validation of the Analytical Procedure}

Quantitative evaluation is based on the linear correlation between the peak current and concentration. For analytical purposes, best response was obtained in the selected media consisting of a $20 \%$ constant amount of methanol for glassy carbon electrode. The best single peak shape, peak current sensitivity, and reproducibility or these techniques were obtained in $0.1 \mathrm{M}$ sulphuric acid solution. The graph of CIP concentration $v s$ the peak current gave linear calibration curves in $0.1 \mathrm{M}$ sulphuric acid using both techniques, indicating a diffusion-controlled process. The linearity of the calibration curve was obtained in the range of $1.0 \times 10^{-6}-4.0 \times 10^{-5} \mathrm{M}$ for both DPV and SWV techniques. Above these concentration ranges, the loss of linearity was probably due to the adsorption of CIP on the electrode surface. Characteristics of these graphs are given in Table 1 . The precision of the method was investigated by repeatedly $(n=5)$ measuring peak potential and peak current of CIP within a day and over three consecutive days for both techniques. LOD and LOQ were calculated as $(3 \mathrm{~s} / \mathrm{m})$ and $(10 \mathrm{~s} / \mathrm{m})$, respectively where $\mathrm{s}$ is standard deviation of response (three runs) and $\mathrm{m}$ is the slope of the calibration curve. LOD and LOQ values confirmed the sensitivity of the proposed methods, were shown in Table 1. These results demonstrated good precision, accuracy and reproducibility [47, 48]. Standard sample solutions were stored at $+4{ }^{\circ} \mathrm{C}$ in the dark and recorded every week. The solutions did not show any appreciable change in assay values even after four week period. However, all solutions used for the validation experiments were freshly prepared to ensure the stability of analyte in the solutions.

Table 1. Regression Data of the Calibration Lines for Quantitative Determination of Ciprofloxacin by DPV and SWV Techniques

\begin{tabular}{|c|c|c|}
\hline Analytical Parameter & DPV SWV & $0.1 \mathrm{M} \mathrm{H}_{2} \mathrm{SO}_{4}$ \\
\hline \hline Medium & $0.1 \mathrm{M} \mathrm{H}_{2} \mathrm{SO}_{4}$ & 0.93 \\
\hline Measured potential $(\mathrm{V})$ & 0.87 & $1.0 \times 10^{-6}-4.0 \times 10^{-5}$ \\
\hline Linearity range $(\mathrm{M})$ & $1.0 \times 10^{-6}-4.0 \times 10^{-5}$ & $1.94 \times 10^{4}$ \\
\hline Slope of the calibration graph $\left(\mu \mathrm{AM}^{-1}\right)$ & $3.49 \times 10^{4}$ & 0.004 \\
\hline Intercept $(\mu \mathrm{A})$ & 0.041 & 0.999 \\
\hline Correlation coefficient & 0.999 & $6.07 \times 10^{-1}$ \\
\hline SE of slope & $4.75 \times 10^{2}$ & $1.01 \times 10^{-3}$ \\
\hline SE of intercept & $7.92 \times 10^{-3}$ & $2.24 \times 10^{-7}$ \\
\hline LOD (M) & $1.27 \times 10^{-7}$ & $7.47 \times 10^{-8}$ \\
\hline LOQ (M) & $4.25 \times 10^{-7}$ & 0.48 \\
\hline Repeability of peak current (RSD \%) & 0.21 & 0.79 \\
\hline Repeability of peak potential (RSD \%) & 0.59 & 0.99 \\
\hline Reproducibility of peak current (RSD \%) & 0.80 & 1.18 \\
\hline Reproducibility of peak potential (RSD \%) & 1.10 & \\
\hline
\end{tabular}




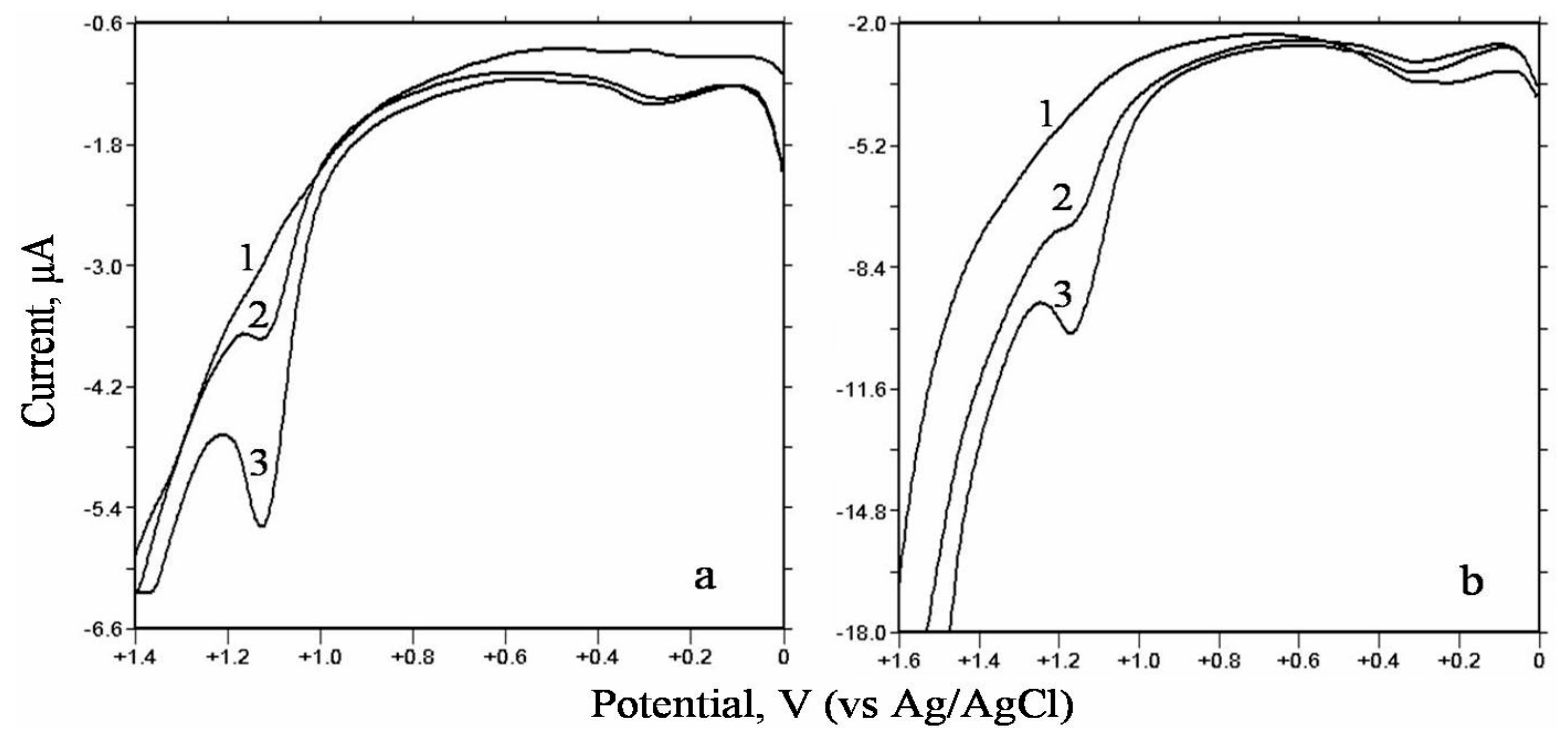

Fig. (4). (a) Differential puls voltammograms (b) Square wave voltammograms in $0.1 \mathrm{M}$ sulphuric acid for the determination of ciprofloxacin in tablet samples; (1) blank, (2) $6.0 \times 10^{-6} \mathrm{M}$, (3) $2.0 \times 10^{-5} \mathrm{M}$.

Table 2. The Results for the Determination of Ciprofloxacin from Tablet Dosage form and Achieved Recovery of DPV and SWV Experiments

\begin{tabular}{|c|c|c|}
\hline Parameter & DPV & SWV \\
\hline Medium & $0.1 \mathrm{M} \mathrm{H}_{2} \mathrm{SO}_{4}$ & $0.1 \mathrm{M} \mathrm{H}_{2} \mathrm{SO}_{4}$ \\
\hline Labelled claim (mg) & 500.00 & 500.00 \\
\hline Amount found ${ }^{*}(\mathrm{mg})$ & 499.65 & 499.69 \\
\hline RSD \% & 1.20 & 1.30 \\
\hline Bias \% & 0.07 & 0.06 \\
\hline Added (mg) & 20.00 & 20.00 \\
\hline Found* (mg) & 19.99 & 19.98 \\
\hline Average recovered $\%$ & 99.93 & 99.88 \\
\hline RSD $\%$ of recovery & 0.43 & 0.96 \\
\hline Bias \% & 0.07 & 0.12 \\
\hline
\end{tabular}

\subsection{Application to Analysis of Pharmaceuticals}

The validity of the proposed DPV and SWV methods at the glassy carbon electrode for the determination of CIP in pharmaceutical dosage forms was investigated by assaying tablet dosage form. Fig. (4) illustrate the response of rise over successive concentration of CIP in tablet dosage form by DPV and SWV voltammetry. Without any sample extraction or filtration step, but just through dissolution and an adequate dilution of the analyte present in the solution of Cipro $^{\circledR}$ tablets, both methods can be used for the direct determination of CIP using the related calibration straight line. Recovery studies were carried out after addition of known amounts of pure drug to various pre-analyzed formulations of CIP. In order to detect interactions of the excipients, the standard addition technique was applied to the same preparations, which were analyzed by calibration curve. The results show that the proposed methods were successfully applied for the assay of CIP in its tablet dosage form (Table 2). The mean results for five determinations of both techniques are very close to the declared value of 500 $\mathrm{mg}$; the confidence limits were calculated for a significance level of 0.05 . The results showed that the proposed methods could be applied with great success for CIP assay in tablet without any interference.

\section{CONCLUSIONS}

The voltammetric oxidation step of CIP in different buffer solutions between $\mathrm{pH}$ 0.3-12.00 has been elucidated. The CIP is irreversibly oxidized at high positive potentials. The electrooxidation method which is found in literature [38] related to the of CIP qualitative determination. The proposed DPV and SWV technique for the determination of CIP in pharmaceutical dosage form was found to be as simple and rapid as the reported method and more selective, sensitive and validated than the reported method [38, 39]. The proposed voltammetric methods can be applied directly to the analysis of pharmaceutical dosage forms without the need for separation or complex sample preparation, since there was no interference from the excipients and endogenous substances. The proposed method is fully validated.

\section{REFERENCES}

[1] Periti, P.; Mazzei, T.; Curti, M.E. Efficacy and safetely of high dose intravenous ciprofloxacin in the treatment of bacterial pneumonia. Int. J. Antimicrob. Agents, 1998, 10, 215.

[2] Van Zanten, A.R.H.; Polderman, K.H.; Van Gijlswijk, I.M; Van der Meer, G.Y.G.; Schouten, M.A.; Girbes, A.R.J. Ciprofloxacin pharmacokinetics in critically ill patients: A prospective cohart study J. Crit. Care, 2008, 23, 422.

[3] Goodman and Gilman's. The Pharmacological Basis of Therapeutics; $11^{\text {th }}$ ed., Brunton, LL.; Ed.; McGraww-Hill Medical Publications Division: New York, NY, 2006.

[4] Huang, J.F.; Feng, Y.Q.; Lin, X.H. Determination of five fluorouinolones in human plasma using polymer monolith microextraction coupled to high performance liquid chromatography. Chin. Pharm. J., 2009, 44, 941. 
[5] Adib, N.; Shekarchi, M.; Kobarford, F.; Hamedani, M.P.; Hajimehdipoo, H.; Rahimifard, A. A new HPLC method for determination of ciprofloxacin in human plasma and its application in bioequivalence studies. Biosci. Biotechnol. Res. Asia, 2008, 5, 583.

[6] Pellegrino, R.M.; Segoloni, F.; Cagini, C. Simultaneous determination of ciprofloxacin and the active metabolite of prulifloxacin in aqueous human humor by high-performance liquid chromatography. J. Pharm. Biomed. Anal., 2008, 3, 567.

[7] Aksoy, B.; Küçükgüzel, I.; Rollas, S. Development and validation of a stability-indicating HPLC method for determination of ciprofloxacin hydrochloride and its related compounds in filmcoated tablets. Chromatographia, 2007, 66, 57.

[8] Espinosa-Monsilla, A.; Munoz de la Pena, A.; Gonzalez Gomez, D.; Canada-Canada, F. HPLC determination of ciprofloxacin, cloxacillin, and ibuprofen drugs in human urine samples. J. Sep. Sci., 2006, 29, 1969.

[9] Van Geijlswijk, I.M.; Van Zanten, A.R.H.; Geert Van Der Meer, Y. Reliable new high performance liquid chromatographic method for the determination of ciprofloxacin in human serum. Ther. Drug Monit., 2006, 28, 278.

[10] Dincel, A.; Yıldırım, A.; Çağlayan, F.; Bozkurt, A. Determination of ciprofloxacin in human gingival creicular fluid by highperformance liquid chromatography. Acta Chromatographica, $\mathbf{2 0 0 5}, 15,308$.

[11] Kassab, N.M.; Sing, A.K.; Kedar-Hackmam, E.R.M.; Santoro, M.I.R.M. Quantitative determination of ciprofloxacin and norfloxacin in pharmaceutical preparations by high performance liquid chromatography. Braz. J. Pharm. Sci., 2005, 41, 507.

[12] Vybiraloa, Z.; Nobilis, M.; Zouloa, J.; Kuetina, J.; Petr, P. Highperformance liquid chromatographic determination of ciprofloxacin in plasma sample. J. Pharm. Biomed. Anal., 2005, 37, 851.

[13] Sowinski, K.M.; Kays, M.B. Determination of ciprofloxacin concentrations in human serum and urine by HPLC with ultraiolet and fluorescence detection. J. Clin. Pharm. Ther., 2004, 29, 381.

[14] Idowu, O.R.; Reggins, J.O. Simple, rapid determination of enrofloxacin and ciprofloxacin in bovine milk and plasma by highperformance liquid chromatography with fluorescence detection. $J$. Pharm. Biomed. Anal., 2004, 35, 143.

[15] Du, L.; Wei, H.; Zhang, J.; Zhang, Q. Separation and determination of six fluoroquinolones by reversed-phase high performance liquid chromatography. Chin. J. Chromatogr., 2003, 21, 503.

[16] Imre, S.; Dogaru, M.T.; Ari, C.E.; Muntean, T.; Keleman, L. Validation of an HPLC method for the determination of ciprofloxacin in human plasma. J. Pharm. Biomed. Anal., 2003, 33, 125.

[17] Samanidou, V.F.; Demetriou, C.E.; Papadoyannis, I.N. Direct determination of four fluoroquinolones, enoxacin, norfloxacin, ofloxacin, and ciprofloxacin, in pharmaceuticals and blood serum by HPLC. Anal. Bioanal. Chem., 2003, 375, 623.

[18] Zotou, A.; Miltiadou, N. Sensitive LC determination of ciprofloxacin in pharmaceutical preparations and biological fluids with fluorescence detection. J. Pharm. Biomed. Anal., 2002, 28, 559 .

[19] Kim, D.H.; Lee, S.K.; Park, Y.H.; Lee, D.W. Determination of ciprofloxacin and its metabolites in urine, using on-line SPE. J. Liq. Chromatogr. Rel. Technol., 2002, 25, 433.

[20] Shafiee, A.; Amini, M.; Khanai, M. Determination of ciprofloxacin in plasma by high-performance liquid chromatography. Indian Drugs, 2002, 39, 110.

[21] Forlay-Frick, P.; Nagy, Z.B.; Fekete, J. Validated determination of ciprofloxacin in influenza vaccine by RP-HPLC. J. Liquid Chromatogr. Rel. Technol., 2001, 24, 827.

[22] Maya, M.T.; Goncalves, N.J.; Silva, N.B.; Morais, J.A. Simple high-performance liquid chromatographic assay for the determination of ciprofloxacin in human plasma with ultraiolet detection. J. Chromatogr. B, 2001, 755, 305.

[23] Krzek, J.; Hubicka, U.; Szczepanczyk, J. High-performance thinlayer chromatography with densitometry for the determination of ciprofloxacin and impurities in drugs. J. AOAC Int., 2005, 88, 1530 .
[24] Noakovic, J.; Nesmerak, K.; Noa, H.; Filka, K. An HPTLC method for the determination and the purity control of ciprofloxacin $\mathrm{HCl}$ in coated tablets. J. Pharm. Biomed. Anal., 2001, 25, 957.

[25] Salem, H.; Fada, L.; Khater, W. Spectrofluorimetric determination of certain fluoroquinolones through charge transfer complex formation. Am. J. Pharmacol. Toxicol., 2007, 2, 18.

[26] Zhang, Z.Q.; Jiang, Y.C.; Yan, H.T. Indirect determination of ciprofloxacin by flow injection flame AAS based on forming complex with Fe(III). Atomic Spectr., 2003, 24, 27.

[27] Xiao, J.B.; Yang, C.S.; Ren, F.L.; Jiang, X.Y.; Xu, M. Rapid determination of ciprofloxacin lactate in drugs by the Rayleigh light scattering technique. Meas. Sci. Technol., 2007, 18, 859.

[28] Dogan-Topal, B.; Uslu, B.; Ozkan, S.A.; Zuman, P. Electrochemical determination of HIV drug abacavir based on its reduction, Anal. Chem., 2008, 80, 209.

[29] Uslu, B.; Dogan-Topal, B.; Ozkan, S.A. Electroanalytical investigation of pefloxacin in pharmaceuticals and serum at borondoped diamond and glassy carbon electrode. Talanta, 2008, 74, 1191.

[30] Uslu, B.; Ozkan, S.A.; Sentürk, Z. Electrooxidation of the antiviral drug valacyclovir and its square-wave and differential pulse voltammetric determination in pharmaceuticals and human biological fluids. Anal. Chim. Acta, 2006, 555, 341.

[31] Uslu, B.; Dogan, B.; Ozkan, S.A, Aboul-Enein, H.Y. Electrochemical behavior of vardenafil on glassy carbon electrode: Determination in tablets and human serum. Anal. Chim. Acta, $\mathbf{2 0 0 5}, 552,127$.

[32] Wang, J.; Ed.; Electroanalytical Chemistry; $3^{\text {rd }}$ ed., Wilay-VCH Pub.: New York, 2006.

[33] Kissinger, P.T.; Heineman W.R.; Eds.; Laboratory Techniques in Electroanalytical Chemistry; $2^{\text {nd }}$ ed., Marcel Dekker: New York, 1996.

[34] Ozkan, S.A.; Uslu, B.; Aboul-Enein, H.Y. Analysis of pharmaceuticals and biological fluids using modern electroanalytical techniques. Crit. Rev. Anal. Chem., 2003, 33, 155.

[35] Smyth, M.R.;Vas, J.G.; Eds.; Analytical Voltammetry; Elsevier Science Pub.: Amsterdam, 1992.

[36] Uslu, B.; Ozkan, S.A. Solid electrodes in electroanalytical chemistry: present applications and prospects for high throughput screening of drug compounds. Comb. Chem. High Throughput Screen., 2007, 10, 495.

[37] Uslu, B.; Ozkan, S.A. Electroanalytical application of carbon based electrodes to the pharmaceuticals. Anal. Lett., 2007, 40, 817.

[38] Komorsky-Lovric, S.; Nigovic, B. Identification of 5aminosalicyclic acid, ciprofloxacin and azitromycin by abrassive stripping voltammetry. J. Pharm. Biomed. Anal., 2004, 36, 81.

[39] Naalon, A.; Blanc, R.; Reyes, L.; Navas, N.; Vilchez, J.L. Determination of the antibacterial enrofloxacin by differentialpulse adsorptive stripping voltammetry. Anal. Chim. Acta, 2002, 454,83 .

[40] Zhang, N.; Zhang, X.; Zhao, Y. Voltammetric study of the interaction of ciprofloxacin-copper with nucleic acids and the determination of nucleic acids. Talanta, 2004, 62, 1041.

[41] Nawaz, H.; Rauf, S.; Akhtar, K.; Khalid, A.M. Electrochemical DNA biosensor for the study of ciprofloxacin-DNA interaction. Anal. Biochem., 2006, 354, 28.

[42] Ionescu, E.R.; Jaffrezic-Renault, N.; Bouffier, L.; Gandran, C.; Cosnier, S.; Pinacho, D.G.; Pilar Marco, M.; Sanches-Baeza, F.J.; Healy, T.; Martelet, C. Impedimetric immunosensor for the specific label free detection of ciprofloxacin antibiotic. Biosens. Bioelectron., $\mathbf{2 0 0 7}, 23,549$.

[43] Laviron, E. ; Roullier, L. ; Degrand, C.J. A multiplayer model for the study of space distributed redox modified electrodes: Part II theory and application of linear potential sweep voltammetry for a simple reaction. J. Electroanal. Chem., 1980, 112, 11.

[44] Barbosa, J.; Barrón, D.; Jiménez-Lozano, E.; Sanz-Nebot. Comparison between capillary electrophoresis, liquid chromatography, potentiometric and spectrophotometric techniques for evaluation of pKa values for zwirterionic drugs in acetonitrile-water mixtures. Anal. Chim. Acta, 2001, 437, 309. 
[45] Goyal, R. N.; Gupta, V. K.; Oyama, M.; Badheti, N. Differential pulse voltammetric determination of atenolol in pharmaceutical formulations and urine using nanogold modified indium tin oxide electrode. Electrochem. Commun., 2006, 8, 65.

[46] Goyal, R. N.; Jain, N.; Gurnani, V. Electrooxidation of chlorpromazinein aqueous and micellar media and spectroscopic studies of the derived cationic free radical and dication species, Monats. Chem., 2001, 132, 575.

[47] Swartz, M.E.; Krull, I.S. Analytical Method Development and Validation; Marcel Dekker: New York, 1997.

[48] Ermer, J.; Miller, JH. Method Validation in Pharmaceutical Analysis; Wiley-VCH: Veinheim, 2005.

Received: May 2, 2010

(C) Uslu et al.; Licensee Bentham Open.

This is an open access article licensed under the terms of the Creative Commons Attribution Non-Commercial License (http://creativecommons.org/licenses/by$\mathrm{nc} / 3.0 /$ ) which permits unrestricted, non-commercial use, distribution and reproduction in any medium, provided the work is properly cited. 